\title{
Visualization of Interactions Between a Pathogenic and a Beneficial Fusarium Strain During Biocontrol of Tomato Foot and Root Rot
}

\author{
Annouschka Bolwerk, Anastasia L. Lagopodi, Ben J. J. Lugtenberg, and Guido V. Bloemberg \\ Leiden University, Institute of Biology Leiden, Wassenaarseweg 64, 2333 AL Leiden, The Netherlands \\ Submitted 25 October 2004. Accepted 7 March 2005.
}

\begin{abstract}
The soilborne fungus Fusarium oxysporum f. sp. radicislycopersici causes tomato foot and root rot (TFRR), which can be controlled by the addition of the nonpathogenic fungus $F$. oxysporum Fo47 to the soil. To improve our understanding of the interactions between the two Fusarium strains on tomato roots during biocontrol, the fungi were labeled using different autofluorescent proteins as markers and subsequently visualized using confocal laser scanning microscopy. The results were as follows. i) An at least 50fold excess of Fo47over $F$. oxysporum f. sp. radicis-lycopersici was required to obtain control of TFRR. ii) When seedlings were planted in sand infested with spores of a single fungus, Fo47 hyphae attached to the root earlier than those of $\boldsymbol{F}$. oxysporum f. sp. radicis-lycopersici. iii) Subsequent root colonization by $F$. oxysporum f. sp. radicis-lycopersici was faster and to a larger extent than that by Fo47. iv) Under disease-controlling conditions, colonization of tomato roots by the pathogenic fungus was significantly reduced. v) When the inoculum concentration of Fo47 was increased, root colonization by the pathogen was arrested at the stage of initial attachment to the root. vi) The percentage of spores of Fo47 that germinates in tomato root exudate in vitro is higher than that of the pathogen $F$. oxysporum $f$. sp. radicis-lycopersici. Based on these results, the mechanisms by which Fo47 controls TFRR are discussed in terms of i) rate of spore germination and competition for nutrients before the two fungi reach the rhizoplane; ii) competition for initial sites of attachment, intercellular junctions, and nutrients on the tomato root surface; and iii) inducing systemic resistance.
\end{abstract}

Fusarium oxysporum f. sp. radicis-lycopersici is the causal agent of tomato foot and root rot (TFRR), which is a serious problem in commercial tomato production (Brayford 1996; Jarvis 1988). Biological control of TFRR by $F$. oxysporum strain Fo47 has been described by Alabouvette and coworkers. To be effective, Fo47 should be introduced at concentrations 10 to 100 times higher than those of the pathogen (Alabouvette and Couteaudier 1992; Alabouvette et al. 1993; Fravel et al. 2003; Paulitz et al. 1987; Roberts and Lohrke 2003).

In previous work, we have analyzed the colonization process of the tomato rhizosphere by $F$. oxysporum f. sp. radicis-

Corresponding author: G. V. Bloemberg; Telephone: +31-71-5275056; Fax: +31-71-5275088; E-mail: Bloemberg@ rulbim.leidenuniv.nl

Current address of A. L. Lagopodi: Aristotelian University of Thessaloniki, Faculty of agriculture, Plant Pathology Laboratory, P. O. box 269, 54006 Thessaloniki, Greece. lycopersici using confocal laser scanning microscopy (CLSM) (Lagopodi et al. 2002) and the interactions between $F$. oxysporum f. sp. radicis-lycopersici and biocontrol Pseudomonas bacteria in the rhizosphere (Bolwerk et al. 2003). These results provided us with new insights into the mechanisms of tomato root infection by $F$. oxysporum f. sp. radicis-lycopersici and of biocontrol of TFRR, respectively. To our knowledge, reports on simultaneous colonization by both a pathogenic and a nonpathogenic biocontrol Fusarium strain are limited (Bao and Lazarovits 2001; Mandeel and Baker 1991) and reports on simultaneous visualization of root colonization by both a pathogenic and a nonpathogenic biocontrol Fusarium strain are scarce (Bao and Lazarovits 2001). In this article, we report the labeling of strains Fo47 and F. oxysporum f. sp. radicis-lycopersici with different autofluorescent proteins followed by an analysis of the tomato root colonization by both fungi simultaneously in relation to disease control. This allowed us to obtain a better understanding of the biocontrol process.

\section{RESULTS}

Cloning of the ecfp and $e y f p$

in pGPDGFP and its expression in Fusarium spp.

Construction of the enhanced green fluorescent-protein (EGFP)-labeled $F$. oxysporum f. sp. radicis-lycopersici derivative FCL14, which was used in CLSM studies, has been described previously (Lagopodi et al. 2002). To be able to distinguish the pathogenic and nonpathogenic $F$. oxysporum strains (Table 1) when visualizing them simultaneously, we constructed derivatives labeled with the enhanced cyan fluorescent protein (ECFP) and the enhanced yellow fluorescent protein (EYFP).

In order to express ecfp in both $F$. oxysporum f. sp. radicislycopersici and F. oxysporum strain Fo47, the ecfp gene was introduced between the Aspergillus nidulans gpdA promoter (Punt et al. 1988) and the $\operatorname{trpC}$ terminator (Mullaney et al. 1985) sequences as follows. Plasmid pGDPGFP (Lagopodi et al. 2002), which contains the $s g f p$ gene between the $g p d A$ promoter and the $\operatorname{trpC}$ terminator, was digested with $\mathrm{NcoI}$ and HindIII in order to isolate the $s g f p$ gene (Fig. 1). The $s g f p$ gene was cloned into an NcoI-HindIII-digested pUC21, which resulted in plasmid pMP4642. Subsequently, pMP4642 was digested with NcoI and BsrgI in order to remove the $s g f p$ gene. The ecfp gene was isolated from pMP4516 (Bloemberg et al. 2000) by NcoI-BsrgI digestion and cloned into the NcoI-BsrgI-digested pMP4642, which resulted in plasmid pMP4650. The pMP4650 plasmid was digested with $N c o$ I and HindIII to isolate the ecfp gene. The NcoI-HindIII $c f p$ gene fragment was ligated into the NcoI- 
HindIII-digested pGDPGFP vector to yield pMP4653 (Fig. $1)$. The same strategy was used to express eyfp in $F$. oxysporum f. sp. radicis-lycopersici. The eyfp gene was isolated from pMP4518 (Bloemberg et al. 2000) by NcoI-BsrgI. Cloning steps identical to those used for the ecfp cloning resulted in the pUC21 derivative pMP4651 and the pGPDGFP derivative pMP4654 (Fig. 1). Fusarium strains were cotransformed as described previously (Lagopodi et al. 2002) using pMP4653 or pMP4654 together with pAN7-1 (Punt et al. 1987). pAN7-1 carries the Escherichia coli hygromycin-B (Hm-B) resistance gene $h p h$, between the gpdA promoter and the $\operatorname{trp} C$ terminator, which allows selection of transformants on media containing Hm-B. Transformants subsequently were selected as described for transformants expressing sgfp by Lagopodi and associates (2002) for i) high levels of ecfp or eyfp expression (10 of $20 \mathrm{Hm}-\mathrm{B}$ resistant transformants), ii) stable ecfp or eyfp expression (9 of 10 fluorescent transformants), iii) unaffected growth, and iv) unaffected pathogenicity for $F$. oxysporum f. sp. radicis-lycopersici and disease control for Fo47. This resulted in FCL55 (F. oxysporum f. sp. radicis-lycopersici expressing eyfp), FCL64 ( $F$. oxysporum f. sp. radicis-lycopersici expressing ecfp), and FCL31 (Fo47 expressing ecfp).

\section{Control of TFRR by the nonpathogenic strain Fo47 in the gnotobiotic sand system.}

Plate confrontation assays were performed to test the antagonistic ability of the nonpathogenic Fo47 against the pathogenic fungus $F$. oxysporum f. sp. radicis-lycopersici. Both fungi were inoculated next to each other on an agar plate and subsequently allowed to grow. In another experiment, the pathogenic fungus was grown on agar plates containing the supernatant fluid of strain Fo47. Growth inhibition of F. oxysporum f. sp. radicis-lycopersici was not observed in these experiments (data not shown). In addition to growth, inhibition of spore germination was analyzed in relation to the antagonistic ability of strain Fo47. Spores of F. oxysporum f. sp. radicis-lycopersici were allowed to germinate in the presence of the culture supernatant of $F$. oxysporum f. sp. radicis-lycopersici or of strain Fo47 grown under nutrient-poor (Armstrong medium, Singelton et al. 1992; synthetic medium, Lorito et al. 1994) and nutrient-rich conditions (potato-dextrose broth). Neither the rate of spore germination nor the total percentage of germinated spores was affected by the supernatant fluid of strain Fo47 (data not shown).

To test whether strain Fo47 could protect tomato plants against TFRR in the gnotobiotic sand system (Simons et al. 1996), tomato seedlings were coated with spores of Fo47. This treatment resulted in a decrease of diseased plants from 100 to $75 \%$. Visualization studies showed that Fo47 colonized only the upper two centimeters, close to the inoculation site, whereas further distribution over the rest of the root was not detected.

In a second strategy to test whether Fo47 can control TFRR in the gnotobiotic system, tomato seedlings were grown in sand infested with spores of $F$. oxysporum f. sp. radicis-lycopersici and Fo47. This strategy was similar to that used by Alabouvette and colleagues (Alabouvette et al. 1992; Alabouvette et al. 1993; Couteaudier 1992; Lemanceau and Alabouvette 1990) for biocontrol. The inoculum concentration of $F$. oxysporum $\mathrm{f}$. sp. radicis-lycopersici was the same in all further experiments $\left(5 \times 10^{4}\right.$ spores $/ \mathrm{kg}$ of sand $)$, whereas the inoculum concentration of strain Fo47 varied between $1 \times 10^{5}$ and $2 \times 10^{9}$ spores $/ \mathrm{kg}$ sand; therefore, the inoculum size will be indicated further in this article as (inoculum) ratio. Different ratios of the pathogenic over the nonpathogenic Fusarium strains were analyzed to determine the minimum inoculum concentration of the nonpathogenic strain Fo47 required for significant biocontrol of TFRR in the gnotobiotic system. After 7 days of incubation, the plants were analyzed for disease symptoms. Healthy plants were scored in disease index (d.i.) 0 and sick plants, with increasing disease severity, were scored in d.i. 1 through 4 (details discussed below).

The presence of Fo47 alone did not affect the health condition of the plants (Table 2). At inoculum ratios $F$. oxysporum $\mathrm{f}$. sp. radicis-lycopersici:Fo47 of 1:2 and 1:10, a decrease in disease severity was observed as is illustrated by a shift from d.i. 3 to d.i. 2 and d.i. 3 to d.i. 1 and 2, respectively (Table 2). Although disease severity was decreased, healthy plants were not observed. Therefore, the inoculum concentration was increased in subsequent experiments and the plants were scored as either healthy or sick.

At an inoculum ratio of 1:50, strain Fo47 reduced the percentage of sick plants from 100 to 58 to $63 \%$ (Table 3). Com-

Table 1. Microorganisms and plasmids

\begin{tabular}{|c|c|c|}
\hline Strains & Relevant characteristics $^{\mathrm{y}}$ & Reference or source \\
\hline \multicolumn{3}{|l|}{ Fungi } \\
\hline ZUM 2407 & Fusarium oxysporum f. sp. radicis-lycopersici causing tomato foot and root rot & IPO-DLO \\
\hline Fo47 & Nonpathogenic $F$. oxysporum, biocontrol agent, isolated from a Fusarium wilt-suppressive soil in France & Alabouvette et al. 1993 \\
\hline FCL14 & ZUM 2407 containing $s g f p$ under control of the constitutive $g p d A$ promoter & Lagopodi et al. 2002 \\
\hline FCL55 & ZUM 2407 containing eyfp under control of the constitutive gpdA promoter & This work \\
\hline FCL64 & ZUM 2407 containing $e c f p$ under control of the constitutive gpdA promoter & This work \\
\hline FCL31 & F. oxysporum Fo47 containing ecfp under control of the constitutive $g p d A$ promoter & This work \\
\hline \multicolumn{3}{|c|}{ 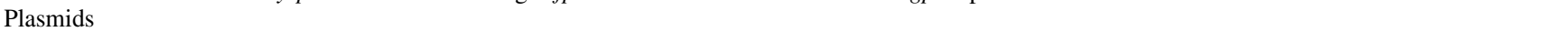 } \\
\hline pUC21 & Cloning vector & Promega/Stratagene \\
\hline pGDPGFP & $\begin{array}{l}\text { pAN52-10-S65TGFPn/n derivative containing } s g f p \text { under the control of the } g p d A \text { promoter; } \\
\text { integrates into the chromosome }\end{array}$ & Lagopodi et al. 2002 \\
\hline pAN 7-1 & $\begin{array}{l}\text { Escherichia coli hygromycin-B (Hm-B) resistance gene } h p h \text {, cloned between the gpdA promoter and the } \\
\text { trpC from Aspergillus nidulans }\end{array}$ & Punt et al. 1987 \\
\hline pMP4516 & pME6010 derivative containing the ecfp gene & Bloemberg et al. 2000 \\
\hline pMP4642 & pUC21 derivative containing the $s g f p$ gene & This work \\
\hline pMP4650 & pUC21 derivative containing the ecfp gene & This work \\
\hline pMP4651 & pUC21 derivative containing the eyfp gene & This work \\
\hline pMP4653 & $\begin{array}{l}\text { pAN52-10-S65TGFPn/n derivative containing ecfp under the control of the } g p d A \text { promoter; } \\
\text { integrates into the chromosome }\end{array}$ & This work \\
\hline pMP4654 & $\begin{array}{l}\text { pAN52-10-S65TGFPn/n derivative containing eyfp under the control of the gpdA promoter; } \\
\text { integrates into the chromosome }\end{array}$ & This work \\
\hline
\end{tabular}

\footnotetext{
${ }^{y}$ IPO-DLO, Wageningen, The Netherlands.

${ }^{\mathrm{z}} s g f p=$ green fluorescent protein, $e y f p=$ enhanced yellow fluorescent protein, $e c f p=$ enhanced cyan fluorescent protein.
} 


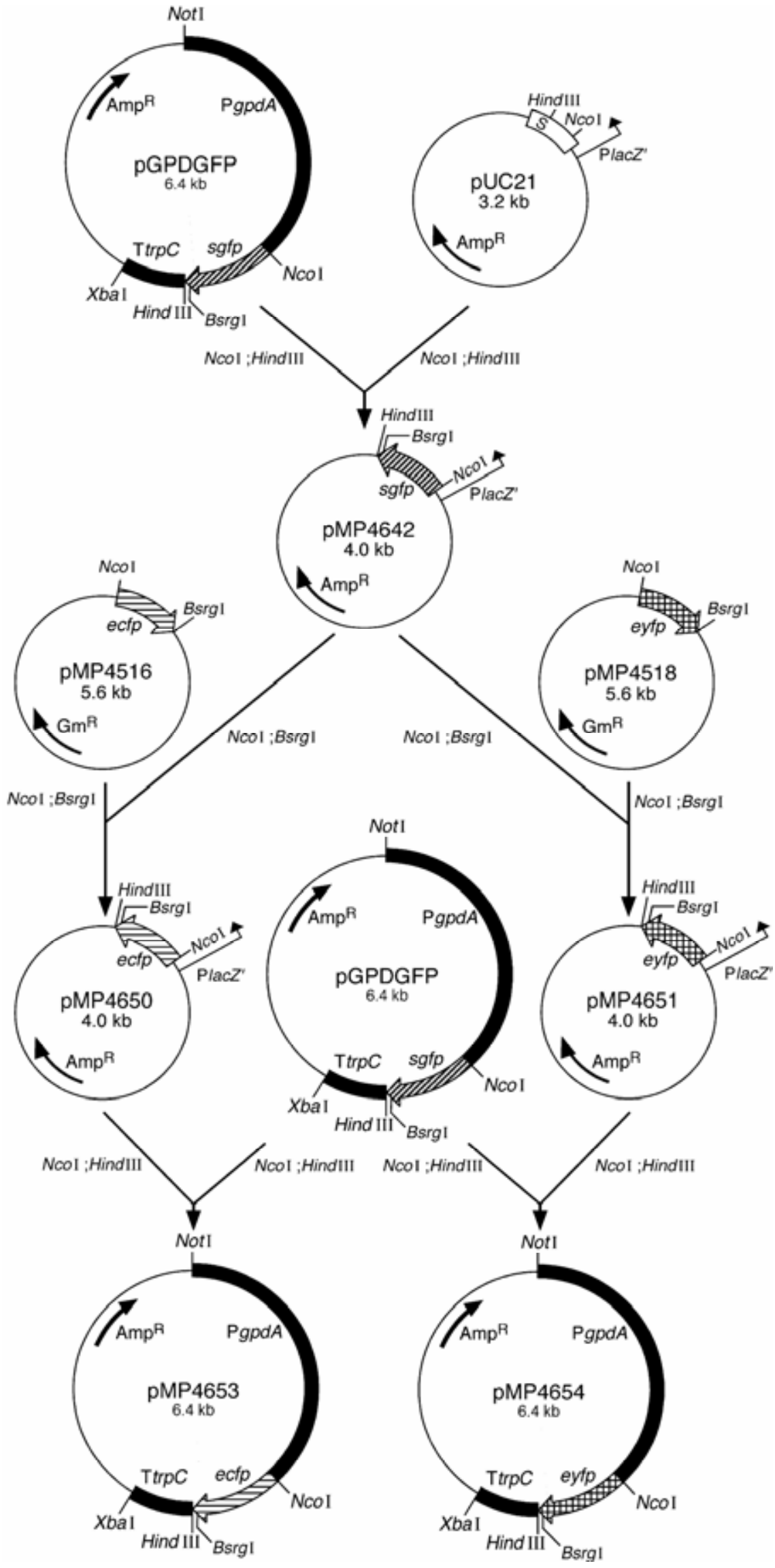

Fig. 1. Construction of reporter plasmids to express enhanced cyan fluorescent protein and enhanced yellow fluorescent protein genes (ecfp and eyfp, respectively) in Fusarium spp. Abbreviations: Amp $=$ ampicillin, $\mathrm{Gm}=$ gentamicin, $\mathrm{P} g p d A=\operatorname{gpdA}$ promoter, $\mathrm{Plac} Z^{\prime}=\operatorname{lac} Z^{\prime}$ promoter, TtrpC $=\operatorname{trpC}$ terminator, $s g f p=$ green fluorescent protein. 
counted as 5 and not as 10 . Subsequently, the difference in root colonization by $F$. oxysporum $\mathrm{f}$. $\mathrm{sp}$. radicis-lycopersici in the absence and presence of Fo47 was statistically analyzed using a Wilcoxon-Mann-Withney $U$ test. The reduction by Fo47 was analyzed at three different $F$. oxysporum f. sp. radicis-lycopersici: $\mathrm{Fo} 47$ ratios (Table 4 ).

Under the disease-reducing condition with an inoculum ratio of 1:10 (Table 2), the nonpathogenic strain Fo47 reduced all colonization stages of the pathogen (Table 4). However, using a Wilcoxon-Mann-Withney $U$ test, it was shown that this reduction of the colonization stages was not significant except for the heavy colonization stage (Table 4). Under diseasecontrolling conditions with inoculum ratios 1:50 and 1:100 (Table 3), strain Fo47 significantly reduced $F$. oxysporum f. sp. radicis-lycopersici in the stage of colonization as well. The heavy colonization stage was not even observed (Table 4). At the ratio 1:100, the pathogen was significantly reduced in the start of colonization (Table 4) as well. Despite the further reduction of the pathogen on the root by Fo47 (Table 4), the higher inoculum concentration (ratio 1:100) did not signifycantly improve the disease-controlling ability of Fo47 (Table 3).

When a much higher inoculum ratio of $F$. oxysporum $\mathrm{f}$. sp. radicis-lycopersici:Fo47 was used $\left(1: 4 \times 10^{4}\right)$, analysis of healthy roots after 7 days showed that root colonization by $F$. oxysporum f. sp. radicis-lycopersici was reduced to the initial state of attachment of hyphae to the root hairs ranging from zero to two sites on the root, compared with the root colonization by $F$. oxysporum f. sp. radicis-lycopersici in all four colonization stages along more than 300 root cells in the absence of strain Fo47 (Table 4).
Temporal analysis of tomato root surface colonization by $\boldsymbol{F}$. oxysporum f. sp. radicis-lycopersici and strain Fo47.

Tomato plants were grown in the gnotobiotic sand system in the presence of spores of $F$. oxysporum $\mathrm{f}$. sp. radicis-lycopersici $\left(5 \times 10^{4}\right.$ spores $/ \mathrm{kg}$ of sand $\left.=5.4 \times 10^{1} \mathrm{spores} / \mathrm{ml}\right)$ or Fo47 $\left(2.5 \times 10^{6}\right.$ spores $/ \mathrm{kg}$ of sand $=2.7 \times 10^{3}$ spores $\left./ \mathrm{ml}\right)$, either alone or together at an inoculum ratio of 1:50. Under the latter condition, Fo47 significantly controlled the disease (Table 3) and significantly reduced root colonization of the pathogen in the colonization and heavy colonization stage (Table 4). Visualization of tomato root colonization in time by Fo47 alone (in two separate experiments with two seedlings per condition) showed that, after 3 days of plant growth, attachment to and start of colonization of the root by Fo47 occurred at two to five sites on the root for each of these stages. Colonization of the tomato root surface was observed after 4 days (Fig. 3), and strongly increased on days six and seven.

Growth of Fo47 hyphae was not targeted strictly to the cellular junctions (Fig. 4A) and occasional penetration of the tomato root by the nonpathogenic strain Fo47 was observed after 3 days (Fig. 4B). The density of the hyphal network reached by strain Fo47 after 7 days (Fig. 4A) was not as high as the heavy colonization network of the pathogen (Fig. 2D).

For the pathogen $F$. oxysporum f. sp. radicis-lycopersici, attachment and start of colonization of the root surface after 3 days was observed at maximally one site on the root surface, for each of these stages. After 4 days, colonization of the tomato root surface was observed along 33 tomato cells over the whole main root and strongly increased at days five and six (Fig. 3). Additionally, the pathogenic Fusarium sp. heavily colo-
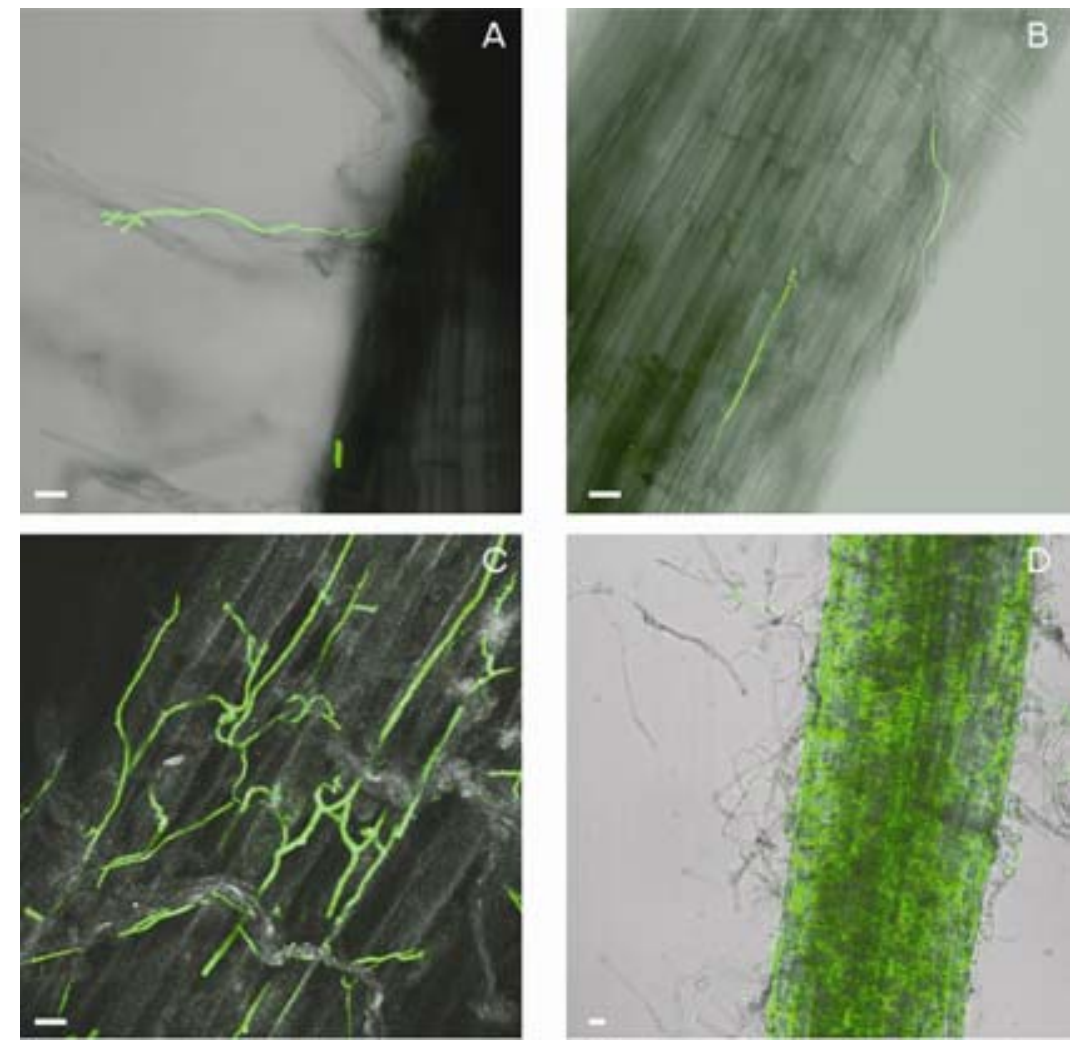

Fig. 2. Confocal laser scanning microscopic analysis of tomato root colonization by Fusarium spp. Two-day-old tomato seedlings were grown in a gnotobiotic sand system containing spores of Fusarium oxysporum f. sp. radicis-lycopersici (FCL14), which harbors a constitutively expressed green fluorescent protein ( $s g f p$ ) gene. Walls of tomato root cells appear as gray due to A, B, and D, contrast light or $\mathbf{C}$, reflected light. A, Initial colonization of the tomato root by $F$. oxysporum f. sp. radicis-lycopersici (similar for Fo47) 'attachment' to root hairs. Subsequent root colonization stages by $F$. oxysporum $\mathrm{f}$. sp. radicis-lycopersici: A, attachment to root hair; $\mathbf{B}$, hyphae growing along the intercellular junctions of two root cells $=$ start colonization stage; $\mathbf{C}$, $F$. oxysporum f. sp. radicis-lycopersici hyphae growing along the intercellular junctions of more than two root cells $=$ colonization stage; $\mathbf{D}$, hyphae growing over the whole root at a very high density and biomass $=$ heavy colonization stage. The size bar represents $10 \mu \mathrm{m}$ in all panels. 
nized the tomato root surface from day five on. The total root surface area heavily colonized by $F$. oxysporum f. sp. radicislycopersici further increased at days six and seven (Fig. 3). In contrast to the nonpathogenic strain Fo47, growth of $F$. oxysporum f. sp. radicis-lycopersici was mainly targeted to the cellular junctions of the root (Fig. 2C).

After inoculation of the sand with a mixture of spores of $F$. oxysporum f. sp. radicis-lycopersici and Fo47, Fo47 was observed to be dominantly present on healthy roots (Fig. 4C). With increased disease index of the plants, colonization of the tomato root surface by $F$. oxysporum f. sp. radicis-lycopersici appeared to be increased relative to colonization by strain Fo47 (compare Fig. 4C with D). On healthy roots, F. oxysporum $\mathrm{f}$. $\mathrm{sp}$. radicis-lycopersici was strongly reduced at all colonization stages till day six (Fig. 5). After 7 days, F. oxysporum f. sp. radicis-lycopersici was strongly reduced at the colonization stage. Heavy colonization was not observed during these 7 days (Fig. 5). Direct cell-to-cell interactions between $F$. oxysporum f. sp. radicis-lycopersici and Fo47 were observed in this period. No stress effects (such as increased branching, swelling of hyphae, or undirected growth of hyphae) (Bolwerk et al. 2003) were observed on any of the fungi upon direct interaction (Fig. 4E and F).

\section{Spore germination on tomato root exudate.}

CLSM studies revealed that Fo47 reduced the pathogen at or before the initial stage of attachment and the subsequent colonization stages under disease-controlling conditions (Fig. 3). A high inoculum ratio $\left(1: 4 \times 10^{4}\right.$ Fo47 spores $/ \mathrm{kg}$ of sand $)$ arrested $F$. oxysporum f. sp. radicis-lycopersici in the attachment stage. To gain more insight into the mechanism causing this strong reduction of $F$. oxysporum $\mathrm{f}$. sp. radicis-lycopersici, spore germination of $F$. oxysporum $\mathrm{f}$. sp. radicis-lycopersici and strain Fo47 in tomato root exudate was analyzed. The composition of tomato root exudate, with respect to amino acids, sugars, and organic acids, has been described previously (Lugtenberg and Bloemberg 2004). It contains glucose (20 $\mu \mathrm{M})$ as the major sugar and citric acid $(133 \mu \mathrm{M})$ as the main organic acid. After incubation overnight in synthetic root exudate, $27 \%$ of the $F$. oxysporum f. sp. radicis-lycopersici spores germinated, whereas a significantly higher percentage $(47 \%)$

Table 4. Quantification and statistical analysis of the influence of Fusarium oxysporum Fo47 on the number of tomato root cells per root colonized by $F$. oxysporum f. sp. radicis-lycopersici ${ }^{\mathrm{y}}$

\begin{tabular}{lrrrr}
\hline & & \multicolumn{3}{c}{ Ratio $^{\mathbf{z}}$} \\
\cline { 3 - 5 } Stage & Alone & $\mathbf{1 : 1 0}$ & $\mathbf{1 : 5 0}$ & $\mathbf{1 : 1 0 0}$ \\
\hline Attachment & $22 \mathrm{a}$ & $16 \mathrm{a}$ & $15 \mathrm{a}$ & $11 \mathrm{a}$ \\
Start colonization & $37 \mathrm{a}$ & $31 \mathrm{a}$ & $19 \mathrm{a}$ & $13 \mathrm{~b}$ \\
Colonization & $229 \mathrm{a}$ & $118 \mathrm{a}$ & $70 \mathrm{~b}$ & $50 \mathrm{~b}$ \\
Heavy colonization & $25 \mathrm{a}$ & $7 \mathrm{~b}$ & $0 \mathrm{~b}$ & $0 \mathrm{~b}$ \\
Total & $313 \mathrm{a}$ & $172 \mathrm{a}$ & $104 \mathrm{~b}$ & $74 \mathrm{~b}$ \\
\hline
\end{tabular}

${ }^{\mathrm{y}}$ Tomato root colonization stages of $F$. oxysporum f. sp. radicis-lycopersici in the absence and presence of Fo47 were classified and quantified after 7 days of growth. The amount of biomass present on root cells heavily colonized by $F$. oxysporum f. sp. radicis-lycopersici is much higher compared with cells colonized by $F$. oxysporum f. sp. radicis-lycopersici. The total number of plant cells per root colonized by $F$. oxysporum f. sp. radicislycopersici is an average of four roots. The inoculum concentration of $F$. oxysporum f. sp. radicis-lycopersici was $5 \times 10^{4}$ spores $/ \mathrm{kg}$ of sand in all cases. The inoculum concentration of $F$. oxysporum Fo47 was 10, 50, or 100 times higher relative to $F$. oxysporum $\mathrm{f}$. sp. radicis-lycopersici.

${ }^{\mathrm{z}}$ The difference in the total number of plant cells colonized by F. oxysporum f. sp. radicis-lycopersici (Alone) or in the presence of strain Fo47 (at three ratios of $F$. oxysporum f. sp. radicis-lycopersici:Fo47) is indicated as not significant (a) or significant (b) as determined by the Wilcoxon-MannWhitney $\mathrm{U}$ test analyzing $F$. oxysporum $\mathrm{f}$. sp. radicis-lycopersici colonization data of eight roots. of Fo47 spores germinated (Fig. 6A). Analysis of spore germination in the major sugar and organic acid showed that a significantly higher percentage of Fo47 spores germinated on both glucose and citric acid (4.4 and $10.7 \%$, respectively) compared with $F$. oxysporum f. sp. radicis-lycopersici ( 0.6 and $6.1 \%$, respectively) (Fig. 6A). Analysis of spore germination in root exudate derived from fresh tomato plant roots confirmed that a significantly higher percentage of Fo47 spores germinate compared with the spores of $F$. oxysporum f. sp. radicis-lycopersici (49 and 33\%, respectively). Over a period of 7 days, the percentage of spores germinated remained constant and the difference between Fo47 and $F$. oxysporum f. sp. radicislycopersici was significant (Fig. 6B).

\section{DISCUSSION}

\section{Previous visualization studies of root colonization} by pathogenic and biocontrol Fusarium strains.

The first reports on visualization focused on the colonization of the root tissue by either a pathogenic (Olivain and Alabouvette 1999; Olivain et al. 2003), or a nonpathogenic Fusarium strain (Olivain and Alabouvette 1997, Olivain et al. 2003) of plants growing in nutrient solutions and using electron microscopy. The use of a $\beta$-glucuronidase construct allowed quantification of the nonpathogenic $F$. oxysporum SA70 on roots of tomato plants grown in soil or potting material (Bao et al. 2000; Eparvier and Alabouvette 1994). Using histochemical staining, Bao and Lazarovitz (2001) were able to simultaneously visualize the pathogenic $F$. oxysporum $\mathrm{f}$. sp. lycopersici and the nonpathogenic $F$. oxysporum SA70 colonizing the outer and the inner root tissue of plants dipped in a spore suspension and subsequently grown in a liquid modified Murashige and Skoog medium. The process of colonization and infection of the tomato root by $F$. oxysporum $\mathrm{f}$. sp. radicis-lycopersici was studied at the end of the past century (Brammall and Higgins 1988; Charest et al. 1984); whereas, more recently, further details were revealed using GFP-labeled F. oxysporum f. sp. radicis-lycopersici (Lagopodi

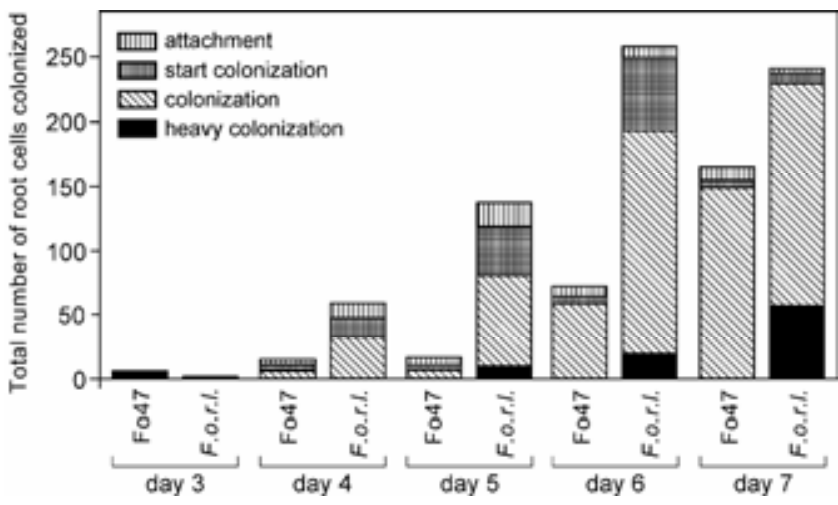

Fig. 3. Quantification of tomato root colonization stages by Fusarium oxysporum f. sp. radicis-lycopersici (F.o.r.l.) and F. oxysporum $\mathrm{Fo} 47$ in time. Seedlings were grown in sand infested with Fo47 $\left(2.5 \times 10^{6}\right.$ spores $/ \mathrm{kg}$ of sand) or $F$. oxysporum $\mathrm{f}$. sp. radicis-lycopersici $\left(5 \times 10^{4}\right.$ spores $/ \mathrm{kg}$ of sand). Plants were scored for tomato root surface colonization after 3, 4, 5, 6, and 7 days of growth. Colonization was classified in four different stages of colonization: attachment, start of colonization, colonization, and heavy colonization. Colonization was quantified by counting the number of plant cells colonized from crown till root tip at the four stages under the following conditions: (i) Fo47 = root colonization of Fo47 in absence of $F$. oxysporum f. sp. radicis-lycopersici and (ii) $F$. oxysporum f. sp. radicis-lycopersici $=\operatorname{root}$ colonization of $F$. oxysporum f. sp. radicis-lycopersici in absence of Fo47. Two plants were scored per condition and the average of two experiments is depicted in the figure. 
et al. 2002). F. oxysporum f. sp. radicis-lycopersici initially appears to attach to the root hairs and subsequently starts to colonize the main root, after which it grows along the intercellular junctions (Lagopodi et al. 2002). At the sites of root penetration, hyphae are swollen and heavy colonization of the tomato root is observed at sites where brown lesions are visible on the root (Lagopodi et al. 2002).

\section{Improved visualization of biocontrol of tomato foot} and root rot by Fo47 using autofluorescently labeled fungi in a gnotobiotic sand-nutrient solution system.

In the present work, we visualized, for the first time under disease-controlling conditions, tomato root colonization by pathogenic and nonpathogenic Fusarium strains simultane- ously. Tomato seedlings were grown in a sterile gnotobiotic sand system infested with spores of $F$. oxysporum f. sp. radicis-lycopersici, Fo47, or both. This system previously was shown to allow visualization of root colonization by Pseudomonas bacteria (Bloemberg et al. 1997, 2000) or F. oxysporum f. sp. radicis-lycopersici (Lagopodi et al. 2002) and of the interaction between $F$. oxysporum f. sp. radicis-lycopersici and biocontrol Pseudomonas bacteria in the tomato rhizosphere (Bolwerk et al. 2003). In order to obtain a better understanding of the biocontrol process, root colonization by F. oxysporum f. sp. radicis-lycopersici and strain Fo47 was visualized, quantified, and statistically analyzed. It should be noted that competing indigenous bacteria are absent in this gnotobiotic system.
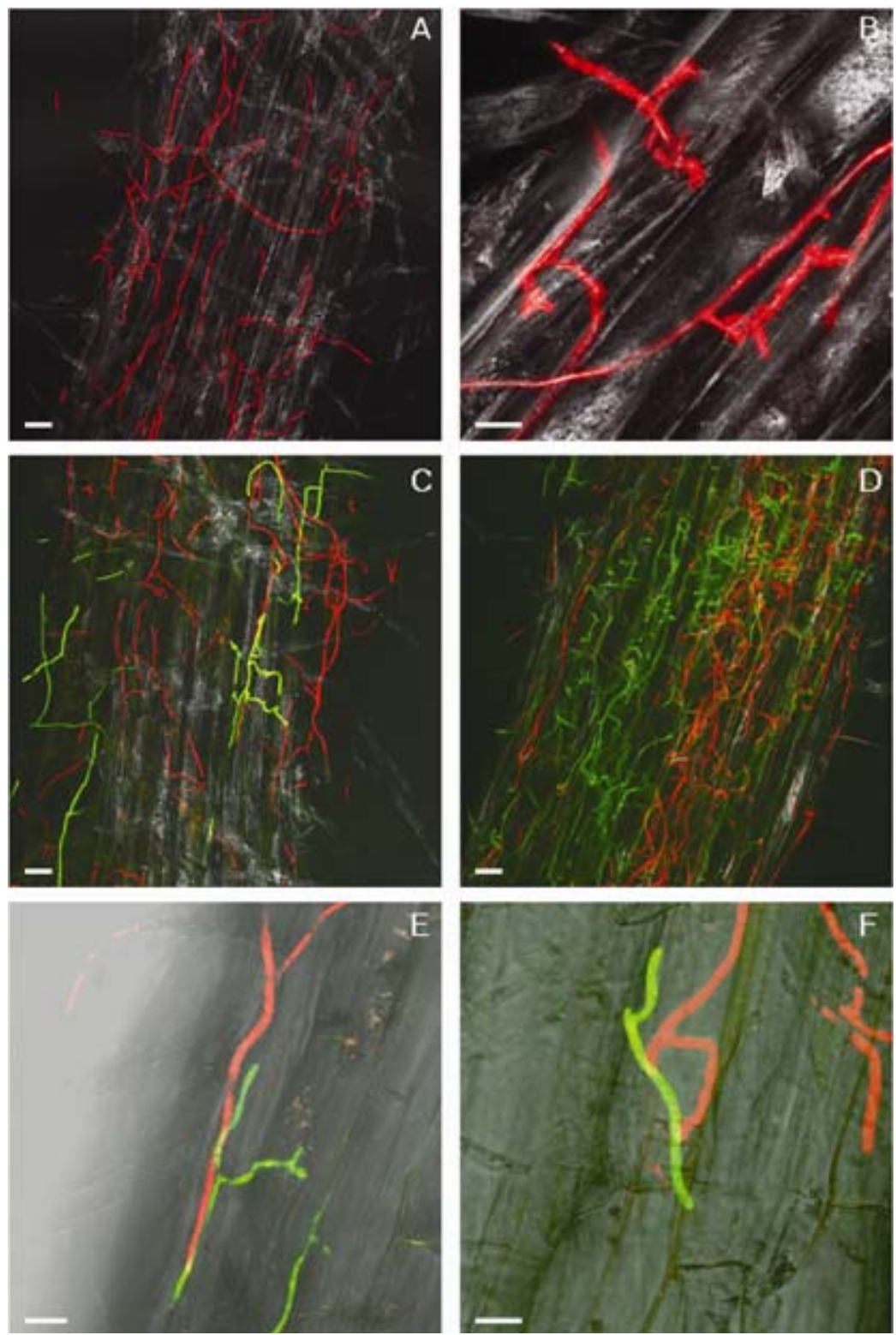

Fig. 4. Confocal laser scanning microscopic analysis of tomato root colonization by the pathogenic fungus Fusarium oxysporum f. sp. radicis-lycopersici and the biocontrol strain Fo47. Two-day-old tomato seedlings were grown in a gnotobiotic sand system containing A and B. spores of Fo47 (FCL31) or C-F, spores of both F. oxysporum f. sp. radicis-lycopersici (FCL14) and Fo47 (FCL31) at an inoculum ratio of 1:50. F. oxysporum f. sp. radicis-lycopersici (FCL14) harbors a constitutively expressed green fluorescent protein ( $s g f p$ ) gene and appears as green. Fo47 (FCL31) harbors a constitutively expressed enhanced cyan fluorescent protein (ecfp) gene; its emission signal is depicted as red in the shown images. Walls of tomato root cells appear as gray due to A$\mathbf{D}$, reflected light or $\mathbf{E}$ and $\mathbf{F}$, contrast light. Colonization of the tomato root by Fo47: A, hyphal growth along cellular junctions and crossing root cells; $\mathbf{B}$, penetration of the tomato root by Fo47 (indicated by an arrowhead). C, On healthy roots (disease index 0), Fo47 is dominant. D, On sick roots with disease index 1 , Fo47 and F. oxysporum f. sp. radicis-lycopersici are equally present. $\mathbf{E}$ and $\mathbf{F}$, Direct cell-to-cell contact between $F$. oxysporum f. sp. radicislycopersici and Fo47 in the rhizosphere. The size bar represents $10 \mu \mathrm{m}$ in all panels. 
Interpretation of the results in relation to mechanisms that could play a role in the control of TFRR by Fo47.

Plate confrontation assays did not show inhibition of the pathogen, and spore germination of $F$. oxysporum f. sp. radicis-lycopersici was not affected by the culture supernatant of Fo47; therefore, it is unlikely that Fo47 produces antibiotics or extracellular enzymes seriously affecting the growth of the pathogen. Direct interactions in the rhizosphere between $F$. oxysporum f. sp. radicis-lycopersici and Fo47 were observed but did not cause stress effects in either of the two fungi (Fig. $4 \mathrm{E}$ and F) such as undirected growth, increased branching, and hyphal swelling, effects described in $F$. oxysporum f. sp. radicis-lycopersici caused by the presence of Pseudomonas chlororaphis PCL1391 (Bolwerk et al. 2003). Therefore, we conclude that i) antibiosis and ii) parasitism and predation as mechanisms for biocontrol of TFRR by Fo47 are unlikely. It cannot be ruled out that, under other conditions, Fo47 does produce inhibitory substances.

Paustian and Schnürer (1987) suggested that C-sources are the growth-limiting factor for fungi in soil. Previously, Couteaudier and Alabouvette (1990) showed that glucose, at concentrations 50 times higher than estimated to be present in tomato root exudate, can be consumed more efficiently by Fo47 than by $F$. oxysporum f. sp. radicis-lycopersici. In this article, we have analyzed spore germination in tomato root exudate and its major sugar (glucose) and organic acid (citric acid) at concentrations estimated to be present in tomato root exudate (Lugtenberg and Bloemberg 2004). It was observed that a higher percentage of Fo47 spores germinated on these three components (Fig. 6A).

Analysis of spore germination in root exudate collected from roots of fresh tomato plants revealed that, over a period of 7 days, a higher percentage of spores of Fo47 germinated compared with spores of $F$. oxysporum $\mathrm{f}$. sp. radicis-lycopersici (Fig. 6B). This would be advantageous for Fo47 in the

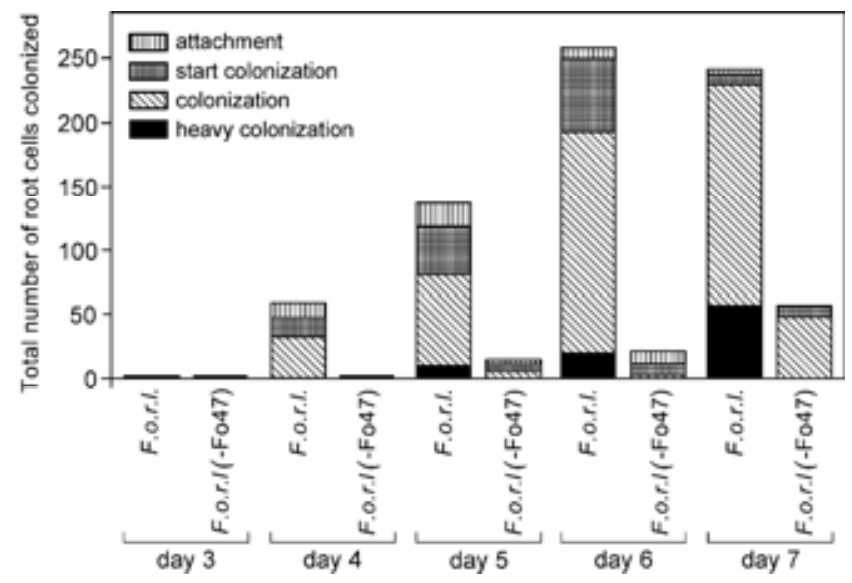

Fig. 5. Quantification of tomato root colonization stages by Fusarium oxysporum f. sp. radicis-lycopersici (F.o.r.l.) in the absence and presence of $F$. oxysporum Fo47 in time. Seedlings were grown in $F$. oxysporum $\mathrm{f}$. sp. radicis-lycopersici $\left(5 \times 10^{4}\right.$ spores $/ \mathrm{kg}$ of sand $)$ or sand infested with $F$. oxysporum f. sp. radicis-lycopersici and Fo47 (ratio 1:50). Plants were scored for tomato root surface colonization after $3,4,5,6$, and 7 days of growth. Colonization was classified in four different stages of colonization: attachment, start of colonization, colonization, and heavy colonization. Colonization was quantified by counting the number of plant cells colonized from crown till root tip at the four stages under the following conditions: (i) $F$. oxysporum f. sp. radicis-lycopersici $=$ root colonization of $F$. oxysporum $\mathrm{f}$. sp. radicis-lycopersici in the absence of Fo47 and (ii) F. oxysporum f. sp. radicis-lycopersici $(-\mathrm{Fo} 47)=\operatorname{root}$ colonization of $F$. oxysporum f. sp. radicis-lycopersici in the presence of Fo47. Two plants were scored per condition and the average of two experiments is depicted in the figure. tomato rhizosphere within the gnotobiotic system, where all nutritional compounds inducing spore germination and supporting hyphal growth are derived from the root exudate. Additionally, the inoculum concentration of Fo47 is 50 times higher than that of $F$. oxysporum f. sp. radicis-lycopersici. These two factors combined will reduce the nutrients available for spore germination and growth of $F$. oxysporum $\mathrm{f}$. sp. radicis-lycopersici. Consequently, fewer $F$. oxysporum f. sp. radicis-lycopersici hyphae will reach the root surface to attach to and colonize the tomato root.

Further reduction of the pathogen, once it has reached the root surface, will be caused by occupation of the root surface by the biocontrol strain Fo47. The root colonization process by the two fungi was shown to contain similar stages and niches. As a consequence, competition for niches on the tomato root involves several sites and stages. The first one is the initial attachment to root hairs (Lagopodi et al. 2002; this study). After 3 days, Fo47 attached to two to five sites on the root, whereas $F$. oxysporum f. sp. radicis-lycopersici attached to no to one site. This is likely to be a result of the higher inoculation concentration of Fo47 and of faster germination of its spores and will result in a reduction of $\mathrm{C}$-sources available for spore germination and growth by $F$. oxysporum f. sp. radicislycopersici. Additionally, this results in a reduction of the number of attachment sites available for $F$. oxysporum $\mathrm{f}$. sp. radicis-lycopersici. The second site is the growth of fungi

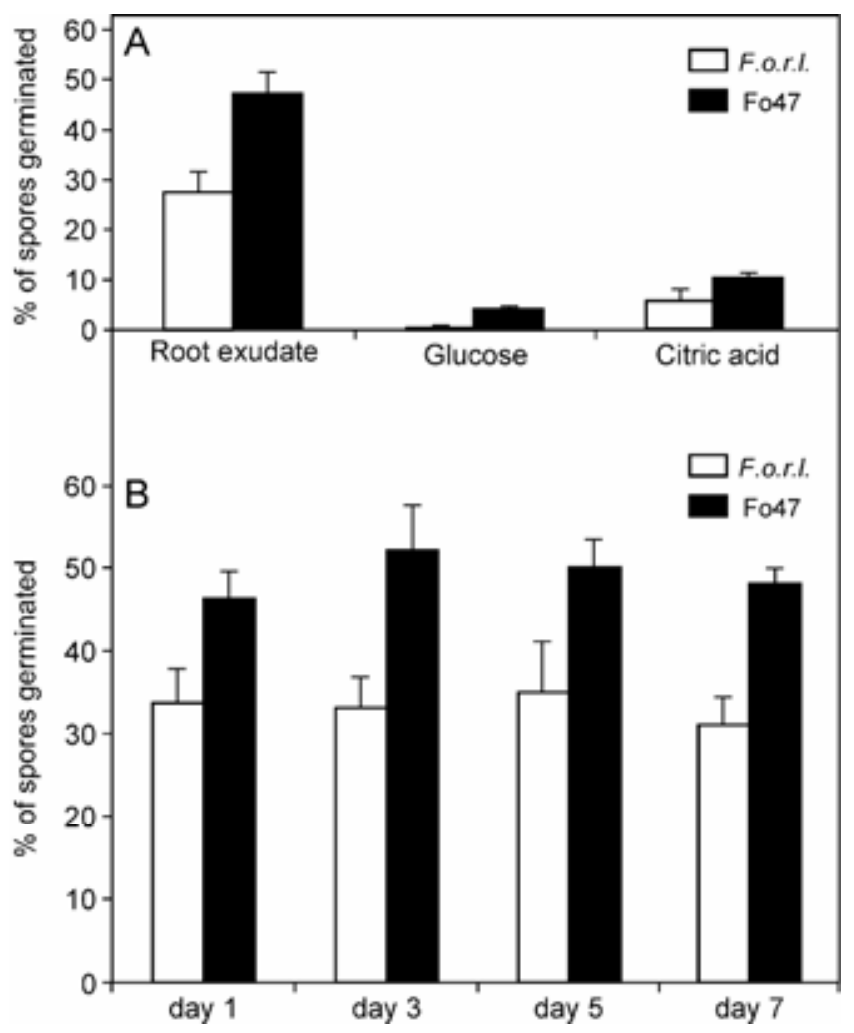

Fig. 6. Germination of Fusarium oxysporum f. sp. radicis-lycopersici (F.o.r.l.) and Fo47spores in tomato root exudate and in solutions of its major sugar and organic acid. A, Spores of $F$. oxysporum f. sp. radicislycopersici and Fo47 were incubated overnight in (i) synthetic root exudate described by Lugtenberg and Bloemberg (2004), (ii) the main exudate sugar glucose $(20 \mu \mathrm{M})$, or (iii) the main exudate organic acid citric acid $(133 \mu \mathrm{M})$. The total number of spores and the number of germinated spores were quantified. Subsequently, the percentage of spore germination was calculated. B, A time course analysis of the spore germination of $F$. oxysporum f. sp. radicis-lycopersici and Fo47 in tomato root exudate derived from plants grown in a hydroponic system. Over a period of 7 days, the percentage of spore germination was calculated every 2 days. 
along the cellular junctions of the root (Figs. 2C and 4A). The presence of $\mathrm{Fo} 47$ at these junctions reduces the sites available for colonization by $F$. oxysporum $\mathrm{f}$. sp. radicis-lycopersici. However, root colonization by Fo47 from day four on was slower and to a lower extent compared with that of $F$. oxysporum f. sp. radicis-lycopersici despite the 50-fold higher inoculum concentration (Fig. 3), as shown by the following observations. i) Five times more root cells were colonized by F. oxysporum f. sp. radicis-lycopersici than by Fo47 (colonization was observed along 33 and 6 root cells, respectively) after 4 days of growth. ii) Colonization by $F$. oxysporum f. sp. radicis-lycopersici increased most strongly at day four versus at day six by Fo47. iii) The total root area colonized after 7 days of growth was larger for $F$. oxysporum f. sp. radicis-lycopersici than for Fo47. iv) The colonization by $F$. oxysporum f. sp. radicis-lycopersici was more dense, as indicated by heavy colonization. The third stage, involving penetration of the root, which was observed for both $F$. oxysporum f. sp. radicis-lycopersici (Lagopodi et al. 2002) and Fo47 (Fig 4B), was less frequent for Fo47 than observed for $F$. oxysporum $\mathrm{f}$. sp. radicis-lycopersici (Lagopodi et al. 2002) and may have been restricted to specific sites of the root that are more frail. We assume that, due to the occupation of penetration sites by Fo47, fewer sites were available for penetration by $F$. oxysporum f. sp. radicis-lycopersici. Consequently, fewer lesions were likely to be formed and no additional nutrients were leaking from the root, thereby preventing the normally extensive growth of $F$. oxysporum f. sp. radicis-lycopersici described by Bolwerk and associates (2003). This hypothesis is supported by our observation that, under biocontrol conditions, heavy colonization was not observed.

The results mentioned above suggest that, under biocontrol conditions, Fo47 uses the mechanism "competition for niches and nutrients" as a biocontrol strategy. However, it should be noted that, in order to be effective, Fo47 must be introduced at an at least 50-fold higher inoculum concentration compared with $F$. oxysporum f. sp. radicis-lycopersici (Tables 3 and 4). The observation that root colonization by the biocontrol strain from day four on is less aggressive, slower, and to a lesser extent than that of $F$. oxysporum $\mathrm{f}$. sp. radicis-lycopersici (Figs. 3 and 4) indicates that Fo47 is not capable of effectively competing with the pathogen for niches and nutrients on the root surface. The higher inoculum concentration presumably is needed to compensate for the poorer root colonization characteristics of Fo47. This is also illustrated by the decrease of root colonization by the pathogen at increasing concentrations of Fo47 (Table 4). In conclusion, our CLSM studies provide strong experimental evidence that the mechanism "competition for niches and nutrients" contributes to the biocontrol by Fo47, as previously suggested by Eparvier and Alabouvette (1994), and that this is the result of excess Fo47 and not of the good colonization properties of Fo47. Because there is a great diversity among strains of $F$. oxysporum $\mathrm{f}$. sp. radicis-lycopersici, care should be taken to generalize the interactions described in this work (such as competition for niches and nutrients) for other Fusarium strains.

A common strategy for introducing a biocontrol agent is seed coating. Coating seed and seedlings with Fo47 spores resulted in a reduction of disease incidence from 100 to $75 \%$. Under these conditions, Fo47 hyphae could be observed only just below the crown region. Fo47 is not applied to the sand and poorly colonizes the root; therefore, it is likely that other mechanisms in addition to competition contribute to the observed disease reduction. This situation resembles a previous observation by Dekkers and associates (2000) of tomato seed coated with mutants of $P$. fluorescens WCS365; the mutants were impaired in efficient root colonization but were not af- fected in their ability to protect the plant against TFRR. Biocontrol by strain WCS365 is thought to act via induced systemic resistance. The ability of Fo47 to induce resistance against Fusarium wilt in tomato was shown by Fuchs and associates (1997). Fo47 and the pathogen F. oxysporum f. sp. lycopersici Fol8 were separated in either space or time, thereby minimizing the role of competition for niches and nutrients in disease control. Inoculation of tomato with Fo47 was correlated with increased levels of PR-1, chitinase, $\beta$-1,3-glucanase (classed as PR-2), and $\beta$-1,4-glucosidase (Duijff et al. 1998; Fuchs et al. 1997), indicating that Fo47 acts via a systemic acquired resistance (SAR)-like mechanism. Typically, like rhizobacteria, Fo47 did not cause visible symptoms, whereas necrosis was associated with pathogen-induced SAR. Therefore, the observed reduced disease incidence in our experiments could be a result of Fo47 inducing resistance in tomato.

To our knowledge, this is the first time that pathogenic and biocontrol fungi have been visualized simultaneously on the tomato root and that colonization of the tomato root surface by these fungi has been quantified. In this report, new experimental results obtained under disease-controlling conditions are provided that extend our understanding of the mechanism involved in biocontrol of TFRR by Fo47. i) Direct antagonism between the biocontrol fungus and pathogen is unlikely to play a role in biocontrol by Fo47. ii) The preferential germination of Fo47 spores by root exudate components is thought to reduce growth of the pathogen toward the root because more hyphae of Fo47 can compete for nutrients from root exudate, and reduce the number of $F$. oxysporum f. sp. radicis-lycopersici hyphae that can compete for attachment sites of the root. iii) The higher inoculum concentration of Fo47 compensates for the less-aggressive growth of Fo47 and, consequently, contributes to effective competition for niches and nutrients on the tomato root. iv) Induced resistance is likely to play a role in controlling TFRR.

\section{MATERIALS AND METHODS}

\section{Fungal isolates and inoculum production.}

The microorganisms used are listed in Table 1. F. oxysporum f. sp. radicis-lycopersici and Fo47 were cultured on potatodextrose agar (PDA) (Difco Laboratories, Detroit) or shaken at 130 to $160 \mathrm{rpm}$ in Armstrong medium (Singleton et al. 1992) for 2 days at $28^{\circ} \mathrm{C}$. F. oxysporum f. sp. radicis-lycopersici spores were isolated as described by Lagopodi and associates (2002). The spores were mixed with quartz sand to a concentration of $5 \times 10^{4}$ spores $/ \mathrm{kg}$ of sand $\left(5.4 \times 10^{1} \mathrm{spores} / \mathrm{ml}\right)$ for $F$. oxysporum $\mathrm{f}$. sp. radicis-lycopersici and $5 \times 10^{4}, 1 \times 10^{5}, 3 \times$ $10^{5}, 5 \times 10^{5}, 2.5 \times 10^{6}, 5 \times 10^{4}$, and $2 \times 10^{9}$ spores $/ \mathrm{kg}$ of sand $\left(5.4 \times 10^{1}, 1.1 \times 10^{2}, 5.4 \times 10^{2}, 2.7 \times 10^{3}, 5.4 \times 10^{3}\right.$, and $2.2 \times$ $10^{6}$ spores/ml, respectively) for Fo47. For analyzing spore germination on citric acid, F. oxysporum f. sp. radicis-lycopersici and Fo47 were grown in modified Armstrong medium: instead of sucrose, citric acid was added as single C-source to a final concentration of $1.3 \mathrm{mM}$. Supernatant for analyzing spore germination was collected from $F$. oxysporum f. sp. radicis-lycopersici and Fo47 grown on potato-dextrose broth (Difco Laboratories), Armstrong (Singleton et al. 1992), or synthetic medium (SM) (Lorito et al. 1994) without colloidal chitin and shaken at 130 to $160 \mathrm{rpm}$ for 2 days at $28^{\circ} \mathrm{C}$.

\section{Transformation of Fusarium spp.}

The construction of the plasmids was carried out using standard cloning techniques (Sambrook et al. 1989). Strains Fo47 and $F$. oxysporum f. sp. radicis-lycopersici were transformed by a polyethylene glycol/ $\mathrm{CaCl}_{2}$-mediated transformation of protoplasts as described by Kistler and Benny (1988) and modified by Mes and associates (1999) with additional modifi- 
cations described by Lagopodi and associates (2002). To select the YFP- or CFP-expressing Hm-B-resistant cotransformants, the colonies were directly observed under a Leica MZFLIII stereo microscope equipped with epifluorescence detection (Leica, Bensheim, Germany). Filter sets tailored to the specific chromophores were used (for EYFP, 500/10-nm with excitation 518/16-nm emission; and, for ECFP, 440/21-nm excitation with 480/36-nm emission).

\section{Control of tomato foot and root rot.}

Tomato seed (provided by R. Scheffer, Syntenga, Enkhuizen, The Netherlands) were sterilized (Simons et al. 1996) and incubated at $4^{\circ} \mathrm{C}$ for 5 days on plant nutrient solution (PNS) (Hoffland et al. 1989) solidified with $1.8 \%$ agar. The seed were incubated for 2 days at $28^{\circ} \mathrm{C}$ to allow germination.

The spatiotemporal analyses as well as the disease-controlling experiments were performed in a gnotobiotic quartz sand system (Simons et al. 1996). The sterile glass tubes were filled with sand moisturized with PNS (10\% vol/wt) and infested with spores of $F$. oxysporum f. sp. radicis-lycopersici and strain Fo47. Tomato seedlings were placed $5 \mathrm{~mm}$ below the surface of the sand. The plants were grown in climate-controlled growth chamber at $21^{\circ} \mathrm{C}, 40 \%$ relative humidity, and 16 $\mathrm{h}$ of light per day. In all, 16 to 19 seedlings were grown per treatment. In case of the seed or seedling coating with spores of Fo47, seed or seedlings were incubated in phosphate-buffered saline containing Fo47 spores $\left(1 \times 10^{9}\right.$ spores $\left./ \mathrm{ml}\right)$ for 15 $\min$. After 7 days of growth, the plants were scored for disease development by eye and classified in d.i. 0 to 4 . These indexes correspond to the following symptoms: $0=$ healthy plants with no visible symptoms of foot and root rot, $1=$ plants with pinpoint size brown spots on the main root or pinpoint size light brown spots on the crown, $2=$ plants with brown spots on the main root and extensive brown discoloration of the crown, $3=$ plants with a wilting appearance and an extensive rot of root and crown, and $4=$ dead plants.

\section{CLSM analysis of tomato roots.}

After growth in the gnotobiotic system, tomato roots were carefully taken out of the sand and gently swirled a few times in sterile water in order to wash away the sand particles. Whole roots were placed directly on glass slides in drops of water and examined using an inverted fluorescence microscope (DMIRBE; Leica) equipped with filter blocks with spectral properties matching those of ECFP, (440/21-nm excitation with 480/36-nm emission; XF114; Chroma, Brattleboro, VT, U.S.A.) or EGFP (470/20-nm excitation with 515-nm long pass emission; I3; Leica), to which the Leica SP scanhead was attached. Dual color images were acquired by sequential scanning with settings optimal for ECFP (excitation with 457-nm argon laser line, emission detection between 470 and $490 \mathrm{~nm}$ ), followed by settings optimal for EGFP (excitation with 488$\mathrm{nm}$ argon laser line, detection of emitted light between 500 and $520 \mathrm{~nm}$ ). Reflected light images were obtained by detection of light at the wavelength used for excitation. The projections of the individual channels were merged in Photoshop 7.0 (Adobe, San Jose, CA, U.S.A.) to facilitate visualization.

To qualify and quantify tomato root surface colonization by F. oxysporum f. sp. radicis-lycopersici and Fo47, four tomato roots per treatment were analyzed. Four different stages of root colonization were identified: i) attachment to root hairs; ii) growth along one to two plant cells on main root, defined as "start colonization"; iii) growth along three or more adjacent cells in length, defined as "colonization"; and iv) dense colonization over the total width of the root surface, defined as "heavy colonization". By using this classification, colonization by the fungi could be categorized.
Quantification of root colonization.

All epidermis cells of a tomato root were examined from the crown to the root tip (length axis) for one of the four colonization stages (discussed above) of colonization by Fusarium hyphae using CLSM. The number of tomato root cells colonized in the length axis (form crown to root tip) was counted. When a hyphae was growing on the intercellular junction between two root cells (in length axes), this was scored as one colonized cell. When five cells in the width axis on the same length-axis position were colonized, it was scored as one colonized cell. If these five cells in the width axis were colonized by Fusarium spp. in more than one of the four defined stages (for example, attachment and colonization), the most progressed stage was scored (in this example, colonization). Each experiment was performed at least twice.

\section{Statistical analysis.}

Plants were classed as healthy (disease index 0) or sick (disease index 1 to 4 ). The difference in health condition (healthy or sick) of plants between two different treatments was statistically analyzed using the $\chi^{2}$ goodness-of-fit test (Heath 1995). The degree of freedom was 1 (degree of freedom $=$ two conditions tested -1$)($ two classes of plants -1$)$ resulting in the critical $\chi^{2}$ value of $3.841(P<0.05)$. The null hypothesis was defined as the lack of significant difference between two conditions tested. To test the null hypothesis, the $\chi^{2}$ value was calculated for the two conditions using the $\chi^{2}$ goodness-of-fit test. If the calculated $\chi^{2}$ value was lower than the critical $\chi^{2}$ value, the null hypothesis was accepted (e.g., the two treatments were not significantly different). When the calculated $\chi^{2}$ value was higher than the critical value, the null hypothesis was rejected (e.g., the treatments differ significantly).

Quantification of tomato root colonization was performed by counting the number of root cells colonized by $F$. oxysporum f. sp. radicis-lycopersici as described above. To determine whether root colonization by $F$. oxysporum f. sp. radicis-lycopersici was significantly reduced by the presence of strain Fo47 after 7 days of incubation, four roots per condition $(F$. oxysporum $\mathrm{f}$. sp. radicis-lycopersici alone and $F$. oxysporum $\mathrm{f}$. sp. radicis-lycopersici in the presence of Fo47; e.g., two conditions) were analyzed. Within this analysis, eight roots in total were scored from root tip to crown for root colonization by $F$. oxysporum f. sp. radicis-lycopersici. A Wilcoxon-Mann-Withney U test (Sokal and Rohlf 1981) was used to determine whether the difference in root colonization by $F$. oxysporum $\mathrm{f}$. sp. radicis-lycopersici in the absence and in the presence of Fo47 was significantly different. This statistical analysis was performed on the three different ratios of $F$. oxysporum $\mathrm{f}$. sp. radicis-lycopersici:Fo47 (1:10, 1:50, and 1:100). Each ratio was analyzed at least twice.

\section{Plate confrontation assays.}

PDA plates were inoculated with agar plugs (four $\mathrm{mm}$ ) of the fungi, placed $4 \mathrm{~cm}$ apart and incubated at $25^{\circ} \mathrm{C}$, and the growth of $F$. oxysporum f. sp. radicis-lycopersici was analyzed daily. Additionally, fungal culture supernatant of strain Fo47 and $F$. oxysporum $\mathrm{f}$. sp. radicis-lycopersici also was analyzed for its ability to inhibit hyphal growth of $F$. oxysporum $\mathrm{f}$. $\mathrm{sp}$. radicis-lycopersici. A $2 \times$ concentrated Armstrong overnight culture $(100 \mu \mathrm{l})$ was plated on one half of a PDA plate and $F$. oxysporum f. sp. radicis-lycopersici was inoculated as a stripe of spores on both halves of the plate. The growth of $F$. oxysporum $\mathrm{f}$. sp. radicis-lycopersici was analyzed daily.

\section{Spore germination.}

Fungal spores of both $F$. oxysporum f. sp. radicis-lycopersici and Fo47 were incubated in tomato root exudate (synthetic as 
described by Lugtenberg and Bloemberg [2004] and collected from roots of fresh growing tomato plants), $20 \mu \mathrm{M}$ glucose, or $133 \mu \mathrm{M}$ citric acid overnight at room temperature. Root exudate was isolated as described previously (Simons et al. 1997). Briefly, $100 \mathrm{ml}$ of sterile seedlings was placed in $100 \mathrm{ml}$ of PNS and allowed to grow in a climate-controlled growth chamber at $20^{\circ} \mathrm{C}, 40 \%$ relative humidity, and $16 \mathrm{~h}$ of daylight. After 14 days of growth, root exudate was collected.

Spore germination on root exudate from fresh tomato plants was analyzed for spores isolated from Armstrong cultures containing sucrose (Singelton et al. 1992). Germination in glucose $(20 \mu \mathrm{M})$ or citric acid $(133 \mu \mathrm{M})$ was analyzed for spores isolated form Armstrong cultures containing sucrose (Singelton et al. 1992) or citric acid (1.3 $\mu \mathrm{M})$, respectively. Spore germination in synthetic root exudate was analyzed for spores isolated from Armstrong cultures.

To analyze whether Fo47 could produce inhibitory substances, we allowed spores of $F$. oxysporum f. sp. radicis-lycopersici to germinate in culture supernatant of Fo47 grown in nutrient-rich (PDA) or nutrient-poor (SM or Armstrong) medium. The corresponding medium was added to this spore suspension in culture supernatant to a final concentration of $0.1 \times$ PDA, $0.02 \times$ SM, or $0.02 \times$ Armstrong.

The reaction volume was $500 \mu \mathrm{l}$ and the final concentration of spores was $2.5 \times 10^{5} / \mathrm{ml}$. After overnight incubation at room temperature, the number of germinated and total number of spores was counted using a hematocytometer and the percentage of germination was calculated. The germination experiments were carried out in triplicate and were repeated twice. Using a Mann-Whitney U test, differences between spore germination of the pathogen and biocontrol agent were evaluated.

\section{ACKNOWLEDGMENTS}

We thank C. Alabouvette for the supply of the nonpathogenic Fusarium strain Fo47 and useful discussions; and A. H. M. Wijfjes, C. A. M. J. J. van den Hondel, and A. F. J. Ram for the help with fungal transformation. A. Bolwerk was supported by a grant of the NWO Earth and Life Sciences Council, project no. 810.35.003. A. L. Lagopodi was financially supported by a Marie Curie Fellowship of the European Community Program Training and Mobility of Researchers under contract ERBFMBICT982930.

\section{LITERATURE CITED}

Alabouvette, C., and Couteaudier, Y. 1992. Biological control of Fusarium wilts with non-pathogenic Fusaria. Pages 415-426 in: Biological Control of Plant Diseases. Plenum Press, New York.

Alabouvette, C., Lemanceau, P., and Steinberg, C. 1993. Recent advances in biological control of Fusarium wilts. Pestic. Sci. 37:365-373.

Bao, J. R., and Lazarovits, G. 2001. Differential colonization of tomato roots by nonpathogenic and pathogenic Fusarium oxysporum strains may influence Fusarium wilt control. Phytopathology 91:449-456.

Bao, J. R., Velema, J., Dobinson, K. F., and Lazarovits, G. 2000. Using GUS expression in a nonpathogenic Fusarium oxysporum to measure fungal biomass. Can. J. Plant Pathol. 22:70-78.

Bloemberg, G. V., O'Toole, G., Lugtenberg, B. J. J., and Kolter, R. 1997. Green fluorescent protein as a marker for Pseudomonas spp. Appl. Environ. Microbiol. 63:4543-4551.

Bloemberg, G. V., Wijfjes, A. H. M., Lamers, G. E. M., Stuurman, N., and Lugtenberg, B. J. J. 2000. Simultaneous imaging of Pseudomonas fluorescens WCS365 populations expressing three different autofluorescent proteins in the rhizosphere: new perspectives for studying microbial communities. Mol. Plant-Microbe Interact. 13:1170-1176.

Bolwerk, A., Lagopodi, A. L., Wijfjes, A. H. M., Lamers, G. E. M., ChinA-Woeng, T. F. C., Lugtenberg, B. J. J., and Bloemberg, G. V. 2003. Interactions in the tomato rhizosphere of two Pseudomonas biocontrol strains with the phytopathogenic fungus Fusarium oxysporum f. sp. radicis-lycopersici. Mol. Plant-Microbe Interact. 11:983-993.

Brammall, R. A., and Higgins, V. J. 1988. A histological comparison of fungal colonization in tomato seedlings susceptible or resistant to Fusarium crown and root rot disease. Can. J. Bot. 66:915-925.
Brayford, D. 1996. Fusarium oxysporum f. sp. radicis-lycopersici, IMI descriptions of fungi and bacteria no. 1270. Mycopathologica 133:61-63.

Charest, P. M., Ouelette, G. B., and Pauze, F. J. 1984. Cytological observations of early infection process by Fusarium oxysporum f. sp. radicislycopersici in tomato plants. Can. J. Bot. 62:1232-1244.

Couteaudier, Y. 1992. Competition for carbon in soil and rhizosphere, a mechanism involved in biological control of Fusarium wilts. Pages 99104 in: Biological Control of Plant Diseases. Plenum Press, New York.

Couteaudier, Y., and Alabouvette, C. 1990. Quantitative comparison of Fusarium oxysporum competitiveness in relation to carbon utilization. FEMS (Fed. Eur. Microbiol. Soc.) Microbiol. Ecol. 74:261-268.

Dekkers, L. C., Mulders, I. H. M., Phoelich, C. C., Chin-A-Woeng, T. F. C., Wijfjes, A. H. M., and Lugtenberg B. J. J. 2000. The sss colonization gene of the tomato-Fusarium oxysporum f. sp. radicis-lycopersici biocontrol strain Pseudomonas fluorescens WCS365 can improve colonization of other wild-type Pseudomonas spp. bacteria. Mol. PlantMicrobe Interact. 13:1177-1183.

Duijff, B. J., Pouhair, D., Olivain, C., Alabouvette, C., and Lemanceau, P. 1998. Implication of systemic induced resistance in the suppression of Fusarium wilt of tomato by Pseudomonas fluorescens WCS417r and by nonpathogenic Fusarium oxysporum Fo47. Eur. J. Plant Pathol. 104:903-910.

Eparvier, A., and Alabouvette, C. 1994. Use of ELISA and GUS-transformed strains to study competition between pathogenic and non-pathogenic Fusarium oxysporum for root colonization. Biocontrol Science Technol. 4:35-47.

Fravel, D., Olivain, C., and Alabouvette, C. 2003. Fusarium oxysporum and its biocontrol. New Phytopathol. 157:493-502.

Fuchs, J.-G., Moënne-Loccoz, Y., and Défago, G. 1997. Nonpathogenic Fusarium oxysporum strain Fo47 induces resistance to Fusarium wilt in tomato. Plant Dis. 81:492-496.

Heath, D. 1995. The chi-squared test for a difference between two population proportions. Pages 216-218 in: An Introduction to Experimental Design and Statistics for Biology. University College London, London.

Hoffland, E., Findenegg, G. R., and Nelemans, J. A. 1989. Solubilization of rock phosphate by rape. Plant Soil 133:161-165.

Jarvis, W. R. 1988. Fusarium crown and root rot of tomatoes. Phytoprotection 69:49-64.

Kistler, H. C., and Benny, U. K. 1988. Genetic transformation of the fungal wilt pathogen, Fusarium oxysporum. Curr. Genet. 13:145-149.

Lagopodi, A. L., Ram, A. F. J., Lamers, G. E., Punt, P. J., van den Hondel, C. A. M. J. J., Lugtenberg, B. J. J., and Bloemberg, G. V. 2002. Novel aspects of tomato root colonization and infection by Fusarium oxysporum f. sp. radicis-lycopersici revealed by confocal laser scanning microscopic analysis and using the green fluorescent protein as a marker. Mol. Plant-Microbe Interact. 15:172-179.

Lemanceau, P., and Alabouvette, C. 1990. Biological control of Fusarium diseases by the association of fluorescent Pseudomonas and non-pathogenic Fusarium. Pages 45-50 in: Plant Growth Promoting Rhizobacteria Report. C. Keel, B. Knoller, G. and Defago, eds. International Union of Biological Sciences, Interlaken, Switzerland.

Lorito, M., Hayes, C. K., Di Pietro, A., Woo, S. L., and Harman, G. E. 1994. Purification, characterization, and synergistic activity of a glucan $1,3-\beta$-glucosidase and an $\mathrm{N}$-acetyl- $\beta$-glucosaminidase from Trichoderma harzianum. Phytopathology. 84:398-405.

Lugtenberg, B. J. J., and Bloemberg, G. V. 2004. Life in the rhizosphere. In: The Pseudomonads. Vol. I: Genomics, Life Style and Molecular Architecture. J-L. Ramos, ed. Kluwer/Plenum Publishers, New York.

Mandeel, Q., and Baker, R. 1991. Mechanisms involved in biological control of Fusarium wilt of cucumber with strains of nonpathogenic Fusarium oxysporum. Phytopathology 81:462-469.

Mes, J. J., Wit, R., Testerink, C. S., de Groot, F., Haring, M. A., and Cornelissen, B. J. C. 1999. Loss of avirulence and reduced pathogenicity of a gamma-irradiated mutant of Fusarium oxysporum f. sp. radicislycopersici. Phytopathology 89:1131-1137.

Mullaney, E. J., Hamer, J. E., Roberti, K. A., Yelton, M. M., and Timberlake, E. 1985. Primary structure of the trpC gene from Aspergillus nidulans. Mol. Gen. Genet. 199:37-45.

Olivain, C., and Alabouvette, C. 1997. Colonization of tomato root by a non-pathogenic strain of Fusarium oxysporum. New Phytopathol. 137:481-494.

Olivain, C., and Alabouvette, C. 1999. Process of tomato root colonization by a pathogenic strain of Fusarium oxysporum f. sp. lycopersici in comparison with a non-pathogenic strain. New Phytopathol. 141:497-510

Olivain, C., Trouvelot, S., Binet, M. N., Cordier, C., Pugin, A., and Alabouvette, C. 2003. Colonization of flax roots and early physiological responses of flax cells inoculated with pathogenic and nonpathogen strains of Fusarium oxysporum. Appl. Environ. Microbiol. 69:5453-5462.

Paulitz, T. C., Park, C. S., and Baker, R. 1987. Biological control of Fusa- 
rium wilt of cucumber with nonpathogenic isolates of Fusarium oxysporum. Can. J. Microbiol. 33:349-353.

Paustian, K., and Schnürer, J. 1987. Fungal growth response to carbon and nitrogen limitation: application of a model to laboratory and field data. Soil Biol. Biochem. 19:621-629.

Punt, P. J., Oliver, R. P., Dingemanse, M. A., Powels, P. H., and van den Hondel, C. A. M. J. J. 1987. Transformation of Aspergillus based on the hygromycine-B marker from Escherichia coli. Gene 56:117-124.

Punt, P. J., Dingemanse, M. A., Jacobs-Meijsing, B. J. M., Powels, P. H., and Van den Hondel, C. A. M. J. J. 1988. Isolation and characterization of the glyceraldehyde-3-phosphate dehydrogenase gene of Aspergillus nidulans. Gene 69:49-57.

Roberts, D. P., and Lohrke, S. M. 2003. United States Department of Agriculture-Agricultural Research Service research programs in biological control of plant diseases. Pest Manage. Sci. 59:654-664.

Sambrook, J. Fritsch, E. F., and Maniatis, T. A. 1989. Molecular Cloning:
A Laboratory Manual, 2nd ed. Cold Spring Harbor Laboratory Press, Cold Spring Harbor, NY, U.S.A.

Simons, M., Permentier, H. J., de Weger, L. A., Wijffelman, C. A., and Lugtenberg, B. J. J. 1997. Amino acid synthesis is necessary for tomato root colonization by Pseudomonas fluorescens strain WCS365. Mol Plant-Microbe Interact. 10:102-106.

Simons, M., van der Bij, A. J., Brand, I., de Weger, L. A., Wijffelman, C. A., and Lugtenberg, B. J. J. 1996. Gnotobiotic system for studying rhizosphere colonization by plant-growth promoting Pseudomonas bacteria. Mol. Plant-Microbe Interact. 7:600-607.

Singleton, L. L., Mihail, J. D., and Rush, C. M., eds. 1992. Methods for Research on Soilborne Phytopathogenic Fungi. American Phytopathological Society Press, St. Paul, MN, U.S.A.

Sokal, R. R., and Rohlf, F. J. 1981. Biometry: The Principles and Practice of Statistics in Biological Research, 2nd ed. W. H. Freeman and Co. New York. 